\title{
Rectal perforation caused by mesalazine enema in a patient with ulcerative colitis
}
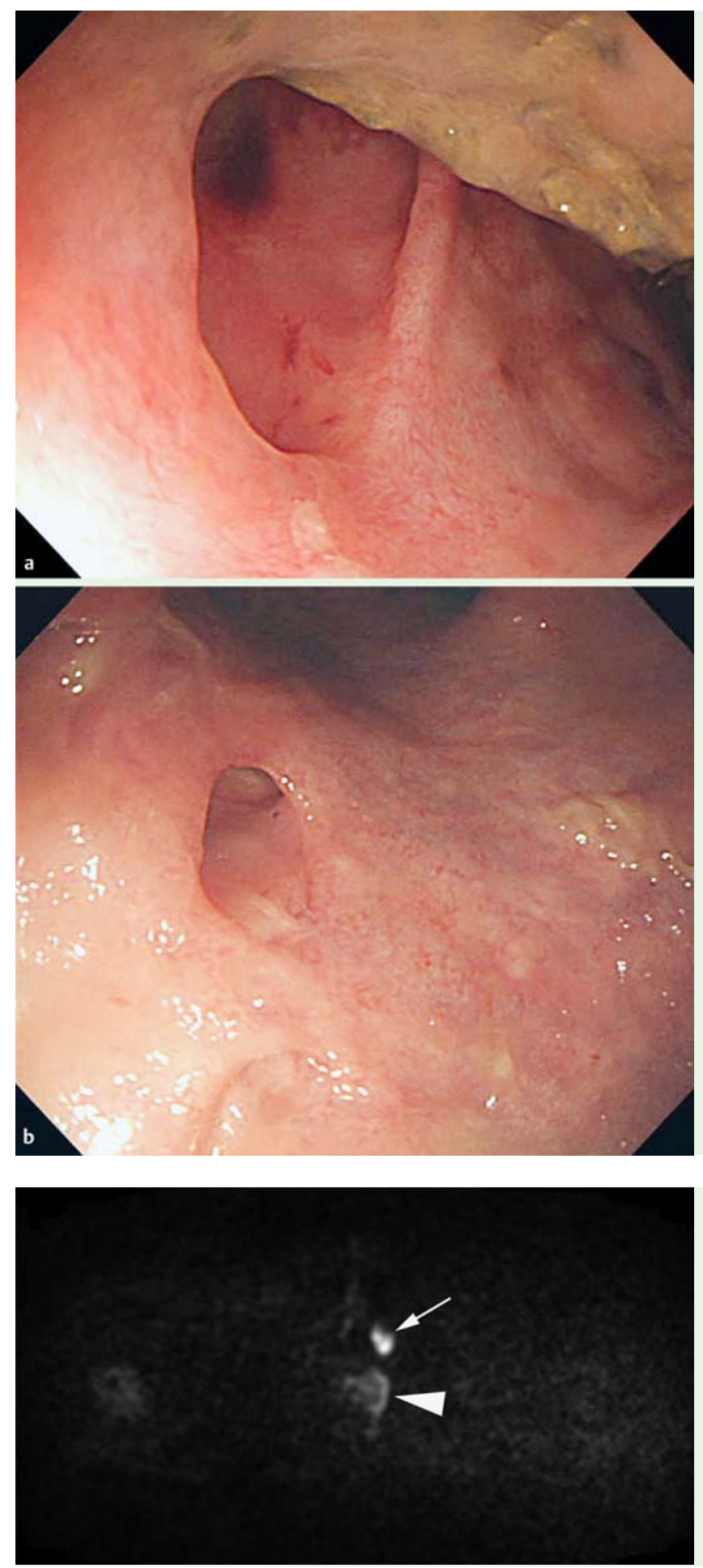

Fig. 2 T2-weighted magnetic resonance imaging showed a continuous localized signal from the left to the dorsal aspect of the anus (arrow) and contiguity from the left side wall of the rectum to the external aspect of the wall (arrow head). Perianal abscess was suspected.

We report on a rare complication of rectal perforation caused by mesalazine enema in a patient with ulcerative colitis.

A 48-year-old woman with ulcerative colitis presented with a relapse of the disease and was started on treatment with mesa- lazine enemas. The patient returned to the hospital 14 days later complaining of perianal pain. Colonoscopy revealed two depressions in the rectum below the peritoneal reflection ( $\mathbf{F i g . 1}$ a); one of the depressions contained a perforation
( $\nabla$ Fig.1b). T2-weighted magnetic resonance imaging showed a continuous localized signal from the left to the dorsal aspect of the anus and contiguity from the left side wall of the rectum to the external aspect of the wall. A perianal abscess was suspected ( $\mathbf{F i g . 2}$ ). Based on these findings, the patient was diagnosed as having a rectal perforation.

After bowel rest and treatment with a steroid and antibiotics, the pain disappeared and remission was achieved. The patient was discharged 10 days later. Colonoscopy after 3 months confirmed leveling out of the two depressions.

The cause of the perforation was thought to be the incorrect insertion method for the mesalazine enema [1]: the patient had held the mesalazine enema in her right hand, and inserted it while standing with legs apart. The correct insertion method requires the patient to lie down on their side with their top leg bent up toward their chest.

Endoscopy_UCTN_Code_CPL_1AJ_2AH

Competing interests: None

Keiichiro Kume, Tatsuyuki Watanabe, Jyunnzi Oshima, Ichiro Yoshikawa, Masaru Harada

Third Department of Internal Medicine, University of Occupational and Environmental Health, School of Medicine,

Kitakyusyu, Japan

\section{References}

1 Tanswell IJ, Irfan K, Kosskowski T et al. Rectal perforation in ulcerative colitis: complication of an enema tip. Gastrointest Endosc 2009; 69: 344

\section{Bibliography}

DOI http://dx.doi.org/

10.1055/s-0034-1365148

Endoscopy 2014; 46: E190

(c) Georg Thieme Verlag KG

Stuttgart · New York

ISSN 0013-726X

\section{Corresponding author}

\section{Keiichiro Kume, MD, PhD}

Third Department of Internal Medicine

University of Occupational and Environmental

Health

School of Medicine

1-1, Iseigaoka, Yahatanishi-ku

Kitakyusyu 807-8555

Japan

Fax: +81-93-6920107

k-kume@med.uoeh-u.ac.jp 